\title{
IS THERE A MARKET FOR BRANDED GULF OF MEXICO OYSTERS?
}

\author{
DANIEL R. PETROLIA* \\ Department of Agricultural Economics, Mississippi State University, Mississippi State, Mississippi \\ WILLIAM C. WALTON \\ School of Fisheries, Aquaculture, and Aquatic Sciences, Auburn University, Auburn, Alabama \\ LAURIANE YEHOUENOU \\ Food and Resource Economics Department, University of Florida, Gainesville, Florida
}

\begin{abstract}
We administered an online choice experiment to a sample of U.S. raw-oyster consumers to identify factors influencing preferences for Gulf of Mexico oysters, determined the extent of preference heterogeneity, and estimated marginal willingness to pay for specific varieties and other key attributes. Results indicate significant preference heterogeneity among select varieties, with non-Gulf respondents estimated to require a price discount on Gulf oyster varieties on the order of \$3-\$6/half dozen. Gulf respondents were found to be less sensitive to oyster variety, and estimated to be willing to pay a price premium only for select Gulf varieties on the order of \$0-\$3/half dozen.
\end{abstract}

Keywords. Best-worst scaling, branding, choice experiment, consumer preferences, economics, labeling, survey, willingness to pay

JEL Classifications. D12, Q22

\section{Introduction}

The U.S. Gulf states of Alabama, Florida, Louisiana, Mississippi, and Texas harvested 8,731 metric tons of the eastern oyster (Crassostrea virginica) in 2013, accounting for more than $75 \%$ of total production for the United States (National Marine Fisheries Service [NMFS], 2014). Yet the value of the Gulf states' harvest represents only $53 \%$ of the total market value because Gulf oysters

\footnotetext{
This research was sponsored by the U.S. Department of Commerce's National Oceanic and Atmospheric Administration (NOAA) under NOAA Award NA10OAR4170078 and the Mississippi-Alabama Sea Grant Consortium, as well as by the U.S. Department of Agriculture National Institute of Food and Agriculture, Multistate Project W-3133 "Benefits and Costs of Natural Resources Policies Affecting Ecosystem Services on Public and Private Lands" (Hatch Project MIS-033140). We extend special thanks to Jim Gossen, Michael Herzog, Rowan Jacobsen, Chris Nelson, Jon Rowley, Robb Walsh, Steve Crockett, Steve LaHaie, and Brian Caswell for their guidance and support throughout the research process.

*Corresponding author's e-mail: d.petrolia@msstate.edu
} 
sell at significantly lower prices relative to those produced in Atlantic and Pacific states (NMFS, 2014). Although many factors affect these prices, the extensive, on-bottom method of oyster farming practiced in Louisiana and other Gulf states has primarily targeted production of large quantities of affordable oysters, which are sold by the sack to processors and typically sold as shucked meats, in sharp contrast to the sales by piece along the northeast Atlantic and Pacific coasts for the live shellstock market. Furthermore, the condition and appearance of extensively cultured oysters is highly dependent on season and harvest location, which can lead to large variation in the quality of the product on the half-shell market.

Although they are the same species, oysters marketed along the Atlantic coast, for example, sell under regional names, such as Wellfleets (from Cape Cod), Blue Points (Long Island), and Chincoteagues (Virginia), and often at a premium. Gulf oysters, on the other hand, are usually sold as cheaper, generic oysters, as Jacobsen (2011) says, "indicative of a region that pays less attention to the nuances of different raw oysters than to their culinary possibilities." The major exceptions on the Gulf coast are Apalachicolas (Florida), which comprise the bulk of Florida's oyster harvest. Although there is no clear evidence that they sell at a premium, there is anecdotal evidence to suggest that a market has developed for these branded oysters and that additional opportunities may exist.

An alternative source of oyster production is off-bottom farm-raised oysters. Although they currently make up only a very small portion of production in the Gulf, they tend to sell at a premium in high-end restaurants because of their superior aesthetic qualities. Since 2009, nearly two dozen off-bottom oyster farms have been established in the Gulf of Mexico region. This alternative production method allows for greater control of aesthetic characteristics, yielding a potentially higher-value product. The potential for geographic branding and a relative shift in focus from quantity to quality provides an opportunity for Gulf oyster producers to reach new markets, increase existing market share, and/or increase market value.

Although previous work has investigated consumer opinions regarding oysters, most studies have provided more general, qualitative findings (Bishop and Peterson, 2005; Grabowski et al., 2003; House, Hanson, and Sureshwaran, 2003; Kow et al., 2008; Martínez-Cordero, Fong, and Haws, 2009; Nell, O'Riordan, and Ogburn, 2006). Several that have taken a more quantitative approach and reported welfare estimates have focused on the effects of postharvest processing and related risk-reduction initiatives on preferences (Bruner et al., 2011; Lin and Milon, 1993; Morgan et al., 2013; Morgan, Martin, and Huth, 2009; Morgan, Whitehead, and Huth, 2015; Whitehead et al., 2012) or preferences as a function of ecosystem services provided (Kecinski, Messer, and Peo, 2016). Manalo and Gempesaw (1997) come closest to the present study in that they utilized a choice experiment to identify preferences over specific attributes, with their focus on price, production method (wild caught vs. farm 
raised), and inspection agency (U.S. Food and Drug Administration vs. U.S. Department of Agriculture). ${ }^{1}$

We are aware of no studies that have addressed consumer preferences for oysters over specific harvest locations/brands, size, and taste (saltiness), and only the one aforementioned study has focused on production method. To our knowledge, this is also the only study that does so on a national scale, including derivation of marginal willingness-to-pay (WTP) estimates for the specific locations/brands and other attributes. We designed and administered an online choice experiment to a panel of U.S. oyster consumers to identify factors influencing preferences for Gulf oysters, to determine the extent of preference heterogeneity among oyster varieties, and to estimate marginal WTP for specific oyster attributes, including harvest location or brand, size, taste (saltiness), and cultivation method (wild vs. farm raised). Methodologically, this study also represents one of very few analyses to utilize best-worst scaling (BWS) as the preference elicitation method within the choice experiment, particularly with an experiment that includes tasting as part of the panelist's evaluation of the alternatives. This approach allows for more efficient preference information extraction per choice set relative to the typical "first-best" choice approach. Because consumers along the Atlantic and Pacific coasts are generally accustomed to choosing from a variety of oysters from a variety of individual producers and locations, which excludes Gulf coast varieties, whereas Gulf coast consumers are accustomed to purchasing cheaper, generic "Gulf" oysters, the experimental design accounts for regional marketing differences by tailoring the choice sets to mimic the choices that a given consumer would make in their respective market.

\section{Experimental Design}

The preference elicitation mechanism for this study was a discrete-choice experiment embedded in an online survey instrument (see Louviere, Hensher, and Swait, 2000; McFadden, 1986; McFadden and Train, 2000). The survey instrument had four sections. The first section focused on raw-oyster consumption patterns of respondents. It first screened for raw-oyster consumers using the question, "Do you eat raw oysters on the half shell at least once per year?" Those that responded yes were then asked about raw-oyster consumption frequency, quantity consumed per meal, and source of oysters (e.g., restaurant, seafood market). Of those that responded no, 107 were randomly selected to answer a brief set of alternative questions. These latter respondents were not included in the present analysis. The second section was the choice experiment. Prior to the choice sets, respondents were introduced to the objective of the choice

1 Overall, research on oyster markets appears to be limited. Beside the studies cited previously that focus on consumer preferences, Dedah, Keithly, and Kazmierczak (2011); Lipton (2008); and Keithly and Diop (2001) analyze various shocks to oyster markets using market data. 
experiment and were given explanations and examples of each attribute. To aid in the size attribute, a photo was provided of a typical small, medium, and large oyster that included an oyster fork for size reference. Respondents were provided an explanation of the alternatives that would be available in each choice set and the available response options. They were informed that they would be asked to evaluate six different choice sets. Then the six choice sets followed. ${ }^{2}$ The third section elicited respondents' perceived food safety and seafood quality ratings for individual water bodies throughout the United States where oysters are harvested. Specifically, we asked respondents: "Please rate what you perceive to be the overall quality of raw oysters on the half shell from the following places, where a 1 is poor and a 10 is excellent." We also asked respondents: "Please rate what you perceive to be the overall level of food safety of seafood in general from the following places, where a 1 is poor and a 10 is excellent." The fourth and final section was a risk-preference exercise (not treated in the present analysis; for details, see Petrolia, 2016).

The experimental design for the choice experiment was a four-alternative (three oyster alternatives plus a "none of the above" option ${ }^{3}$ ), 24-row, fourblock design (so that each respondent evaluated six choice sets), generated using Ngene software, and was optimized according to S-efficiency (ChoiceMetrics, 2012). ${ }^{4}$ There were two separate designs based on whether a generic Gulf oyster was included as one of the alternatives. Because cheaper, generic Gulf oysters are the typical type of oysters sold in the Gulf region, a survey was designed that included a lower-priced generic Gulf oyster as a fixed third alternative. The design was constrained so that the generic Gulf oyster price was always less than the other branded alternatives offered in a given choice set. To account for this price differential, we specify the price variable as the price difference of the branded oyster alternatives relative to the base generic oyster (i.e., the generic oyster alternative's price is normalized to zero). This survey design was administered to Gulf households only. An alternative survey design was administered that did not include the generic Gulf alternative, but rather included only branded oysters. This design was administered primarily to non-Gulf (i.e., Atlantic coast, Pacific coast, and inland) respondents, although a small number of these were administered to Gulf respondents as well. Although it would have been feasible to administer the design that included generic Gulf oysters to non-Gulf consumers, we decided to administer a design that most closely mimicked the actual market in which a given respondent would purchase oysters.

2 We did not use any of the typical strategies for mitigating hypothetical bias, such as a cheap talk script or a reminder about budget, so we readily acknowledge the potential for hypothetical bias.

3 It turned out that very few respondents chose the opt-out alternative, so for the econometric analysis, we dropped the observations of the few that did this and modeled only the three oyster alternatives.

4 To generate an S-efficient design, it is necessary to assume prior parameter estimates. The priors used in the present study were based on the results of a conditional logit regression model estimated over choice data collected during pretesting of the survey. 
Table 1. Attributes and Their Levels Used in the Online Survey Experimental Design (the "lowinformation" treatment included only the oyster variety and price per half dozen, whereas the "high-information" treatment included all of the attributes listed)

Oyster varieties

Gulf coast: Apalachicola Bay (Florida), Bay St. Louis (Mississippi), Champagne Bay (Louisiana), Lonesome Reef (Galveston Bay, Texas),

Point aux Pins (Grand Bay, Alabama), Portersville Bay (Alabama), Gulf of Mexico (generic)

Atlantic coast: Cape Cod (Massachusetts), Chesapeake Bay (Virginia), Moonstones (Point Judith Pond, Rhode Island)

Pacific coast: Hood Canal (Washington), Netarts Bay (Oregon), Willapa Bay (Washington)

Production method Cultivated, wild

Size Small, medium, large, sizes vary*

Saltiness Sweet, mildly salty, salty, saltiness varies*

Price per half dozen $\quad \$ 7^{*}, \$ 8, \$ 9^{*}, \$ 10, \$ 11^{*}, \$ 12, \$ 14, \$ 16, \$ 18$

Notes: Asterisk $\left({ }^{*}\right)$ applies to generic Gulf oyster only.

Attributes included oyster brand/name, price per half dozen, size, saltiness level, and production method (wild or cultivated). All nonprice attribute levels were specified as discrete (i.e., binary) variables, and price was specified as continuous, in units of dollars per half dozen oysters. A total of 13 oyster varieties were included in the design: 7 Gulf varieties, including the "generic" Gulf oyster; 3 Atlantic varieties; and 3 Pacific varieties. ${ }^{5}$ For the generic Gulf oyster only, size was described as "sizes vary," and saltiness was described as "saltiness varies" to reflect the true variation in size and saltiness found in a typical order of generic Gulf oysters. ${ }^{6}$ All other oyster varieties took on one of the specific levels (i.e., "small”, "medium", or "large"; "sweet", "mildly salty", or "salty"). ${ }^{7}$ Table 1 contains a summary of the attributes and their levels used in the online survey.

Choice set responses were elicited using the BWS format (Louviere, Flynn, and Marley, 2015). BWS has emerged of late as an alternative to the format of having respondents indicate only their first-best choice (Flynn and Marley, 2014; Flynn et al., 2007; Marley and Louviere, 2005; Potoglou et al., 2011; Rigby, Burton, and Lusk, 2015; Scarpa et al., 2011). The BWS format asks respondents to indicate the "best" alternative and then to indicate the "worst" alternative, and of the remaining alternatives, they are asked to indicate the "best" of those remaining and then the "worst," and so forth, until a full ranking is achieved. The

5 One of the major advantages of branded oysters over the commodity oysters typically marketed in the Gulf region is their uniformity in size, shape, and/or taste. Thus, it was necessary that we highlight this distinction between the generic and the branded oysters.

6 One of the major advantages of branded oysters over the commodity oysters typically marketed in the Gulf region is their uniformity in size, shape, and/or taste. Thus, it was necessary that we highlight this distinction between the generic and the branded oysters.

7 Exceptions to this were to reflect the true constraints on the characteristics of particular oyster varieties: the production method of Point aux Pins was fixed at "cultivated," and the saltiness level of Hood Canal oysters was constrained to be either "mildly salty" or "salty." 
argument is made that choosing "bests" and "worsts" is a relatively easy task for respondents and yields more information per choice set than the standard question format. Thus, it represents a further extension of the discrete-choice experiment format with the potential to increase survey administration cost efficiency even further.

The present format is an application of “case III" BWS (the multiprofile case; see Flynn and Marley, 2014), included a single question with three alternatives, and elicited the "best" and "worst" choice of the three alternatives, thus yielding a full ranking. This ranking was then decomposed following the method of rankorder explosion proposed by Chapman and Staelin (1982), which, in this case, yields two choice observations for each choice set evaluated: a three-alternative observation (first-best case) and a two-alternative observation (second-best case).$^{8}$ In this particular context, respondents were asked to indicate which of the three alternatives they were "Most Likely to Buy" at the posted prices (i.e., "best") and which of the three alternatives there were "Least Likely to Buy" at the posted prices (i.e., "worst") (Figure 1).

The GfK Group (formerly Knowledge Networks) administered the survey instrument online to a sample of households participating in their Knowledge Panel, a nationally representative and probability-based online panel. The target population was consumers of raw oysters on the half shell. Specifically, it consisted of general population English-speaking adults (age 18+) who reside in one of the U.S. metropolitan statistical areas (MSAs; as defined by the U.S. Census) identified by the authors as being key markets for raw-oyster consumption and who responded yes to the screening question. ${ }^{9}$

Survey design was informed by three previously conducted in-person choice experiments that included oyster tasting (conducted on December 7, 2012; February 13, 2013; and November 11, 2013) consisting of 169 total participants. The draft instrument was then reviewed by an advisory panel consisting of subject matter experts ${ }^{10}$ and revised according to their feedback. A penultimate version of the survey instrument was then pretested on 18 panelists on April

8 Let $\mathrm{A}$ and $\mathrm{B}$ represent a pair of alternatives in a choice set. The second-best case operates under the assumption that the probability of A being chosen as "worst" is equal to the probability of B being chosen as "best."

9 Non-Gulf respondents were sampled from the following MSAs: Baltimore-Towson, MD; BostonCambridge-Quincy, MA-NH; Charleston-North Charleston, SC; Chicago-Naperville-Joliet, IL-IN-WI; Las Vegas-Paradise, NV; New York-Newark-Edison, NY-NJ-PA; Portland-South Portland, ME; St. Louis, MO-IL; San Francisco-Oakland-Fremont, CA; Seattle-Tacoma-Bellevue, WA; and WashingtonArlington-Alexandria, DC-VA. Gulf respondents were sampled from Atlanta-Sandy Springs-Marietta, GA; Baton Rouge, LA; Houston-Baytown-Sugar Land, TX; Jacksonville, FL; Miami-Ft. LauderdaleMiami Beach, FL; Mobile, AL; New Orleans-Metairie-Kenner, LA; Tallahassee, FL; and Tampa-St. Petersburg-Clearwater, FL.

10 Our advisory panel included Jim Gossen (distributor, Louisiana Foods), Michael Herzog (director of food and beverage, Grand Hotel Marriott Resort, Point Clear, AL), Rowan Jacobsen (author of $A$ Geography of Oysters: The Connoisseur's Guide to Oyster Eating in North America), Chris Nelson (oyster 


\begin{tabular}{|l|l|l|l|}
\hline Oysters on the Half Shell & $\begin{array}{l}\text { Price per Half } \\
\text { Dozen }\end{array}$ & $\begin{array}{l}\text { Most Likely to } \\
\text { Buy }\end{array}$ & $\begin{array}{l}\text { Least Likely to } \\
\text { Buy }\end{array}$ \\
\hline $\begin{array}{l}\text { Point aux Pins, Grand Bay, Alabama } \\
\text { Cultivated oysters, medium sized, mildly salty }\end{array}$ & $\$ 12$ & & \\
\hline $\begin{array}{l}\text { Cape Cod, Massachusetts } \\
\text { Wild oysters, small size, sweet }\end{array}$ & $\$ 18$ & & \\
\hline $\begin{array}{l}\text { Gulf of Mexico } \\
\text { Wild oysters, sizes vary, saltiness varies }\end{array}$ & $\$ 9$ & & \\
\hline
\end{tabular}

[ ] I am not willing to buy any of these oysters at these prices.

\begin{tabular}{|l|l|l|l|}
\hline Oysters on the Half Shell & $\begin{array}{l}\text { Price per Half } \\
\text { Dozen }\end{array}$ & $\begin{array}{l}\text { Most Likely to } \\
\text { Buy }\end{array}$ & $\begin{array}{l}\text { Least Likely to } \\
\text { Buy }\end{array}$ \\
\hline Apalachicola Bay, Florida & $\$ 10$ & & \\
\hline Willapa Bay, Washington & $\$ 16$ & & \\
\hline Chesapeake Bay, Virginia & $\$ 12$ & & \\
\hline
\end{tabular}

[ ] I am not willing to buy any of these oysters at these prices.

Figure 1. Example Choice Sets for Online Survey (top: high-information including generic Gulf oyster; bottom: low-information not including generic Gulf oyster)

9-10, 2013, and the final version administered, in two waves, on April 16-May 2 and November 7-18, 2013. A total of 6,879 panelists were sampled from GfK's Knowledge Panel, and of these, 3,807 agreed to be interviewed. A total of 730 responded yes to the screening question, for a $19 \%$ incidence rate (i.e., the rate of those that eat raw oysters at least once per year), and continued to complete the main survey.

\subsection{Empirical Models}

It is assumed that respondent $i$ chooses oyster alternative $j$ if and only if the level of utility associated with alternative $j$ is greater than the level of utility associated

processor and distributor, Bon Secour Fisheries), Jon Rowley (noted food critic and a leader of the "oyster revival”), and Robb Walsh (food critic and author of Sex, Death \& Oysters). 
with the remaining alternatives $\sim j$. We adopt a random-utility framework (see Lancaster, 1966; Marschak, 1960; McFadden, 1974; Thurstone, 1927) wherein utility is composed of two components: observables, which in this case are the attribute levels of the given oyster alternatives, and unobservables, which are those factors known to the respondent that affect utility but unknown to the researcher. Because each respondent evaluated multiple choice sets, it is necessary to adopt an empirical model that accounts for the panel nature of the data. Furthermore, it is hypothesized that preferences over the oyster varieties are not fixed throughout the sample, but rather are heterogeneous. To account for both of these issues, we adopt a random coefficients logit model and specify oyster variety coefficients to follow a normal distribution. Thus, distinct coefficient values are estimated for each respondent (note that the panel specification constrains these coefficients to be equal across observations for the same respondent). Following Carson and Czajkowski (2013), the coefficient on price is exponentiated, the effect of which is that the support of the price parameter is restricted to be in the positive domain and the resulting ratios of attribute parameters and the price parameter will have well-defined moments. The coefficients on the remaining attributes are fixed across the sample; these attributes include size (small, medium, or large), saltiness level (sweet, mildly salty, or salty), and production method (wild caught or cultivated).

Collecting all of the aforementioned issues discussed previously, utility may be specified empirically as $U_{i j}=\left(\boldsymbol{\beta}_{j}+\boldsymbol{\sigma}_{i j}\right)^{\prime} \boldsymbol{x}_{i j}$, where $\boldsymbol{\beta}_{j}$ is a vector of fixed coefficients associated with alternative-specific attributes $\mathbf{x}_{i j}$, and $\sigma_{i j}$ is a random term capturing preference heterogeneity over the oyster brand/location attributes only. Price was specified as a continuous variable, whereas all others were specified as discrete indicator variables. All regression models for the online survey data were estimated using NLOGIT's "rplogit" routine with panel specification (Greene, 2012).

\section{Results}

\subsection{Sample Overview}

A total of 730 respondents indicated that they eat raw oysters on the half shell at least once per year. Of these, 455 respondents are classified as Gulf respondents and 275 are classified as non-Gulf respondents (see footnote 9). Table 2 contains a summary of descriptive statistics for the sample, broken down by Gulf and nonGulf respondents, and includes both oyster eaters (i.e., those who responded yes to the screening question and the small comparison sample of non-oyster eaters that responded no to the screening question). Two sets of tests of differences were conducted across samples: comparing oyster eaters with non-oyster eaters for both Gulf and non-Gulf respondents, and comparing Gulf oyster eaters with non-Gulf oyster eaters. Significant differences (based on $t$-tests for persons per 
Table 2. Comparison of Sample Descriptive Statistics to Census Data for Study Markets

\begin{tabular}{|c|c|c|c|c|c|c|}
\hline & \multicolumn{3}{|c|}{ Gulf Respondents } & \multicolumn{3}{|c|}{ Non-Gulf Respondents } \\
\hline & \multicolumn{2}{|c|}{ Sample } & \multirow[b]{2}{*}{ Census Range } & \multicolumn{2}{|c|}{ Sample } & \multirow[b]{2}{*}{ Census Range } \\
\hline & $\begin{array}{l}\text { Eats } \\
\text { Oysters }\end{array}$ & $\begin{array}{l}\text { Does } \\
\text { Not }\end{array}$ & & $\begin{array}{l}\text { Eats } \\
\text { Oysters }\end{array}$ & $\begin{array}{l}\text { Does } \\
\text { Not }\end{array}$ & \\
\hline $\mathrm{N}=$ & 444 & 72 & & 269 & 35 & \\
\hline Age $65+(\%)$ & 0.23 & 0.21 & $0.08-0.16$ & 0.20 & 0.29 & $0.10-0.14$ \\
\hline Male $(\%)^{*}, \dagger$ & 0.47 & 0.32 & $0.50-0.53$ & 0.67 & 0.63 & $0.49-0.53$ \\
\hline White (\%) & 0.65 & 0.68 & $0.33-0.73$ & 0.69 & 0.77 & $0.30-0.85$ \\
\hline $\begin{array}{l}\text { Persons per } \\
\text { household }\end{array}$ & 2.48 & 2.29 & $2.30-2.70$ & 2.58 & 2.49 & $2.10-2.80$ \\
\hline $\begin{array}{l}\text { High school } \\
\text { graduate } \\
(\%)\end{array}$ & 0.96 & 0.96 & $0.72-0.93$ & 0.95 & 1.00 & $0.80-0.93$ \\
\hline $\begin{array}{l}\text { College } \\
\text { graduate } \\
(\%)^{*}\end{array}$ & 0.50 & 0.43 & $0.24-0.49$ & 0.58 & 0.46 & $0.22-0.58$ \\
\hline $\begin{array}{l}\text { Household } \\
\text { income } \\
\text { category* }\end{array}$ & $\begin{array}{l}\$ 40,000 \\
-\$ 49,999\end{array}$ & $\begin{array}{l}\$ 40,000 \\
-\$ 49,1000\end{array}$ & $\begin{array}{l}\$ 30,858 \\
-\$ 52,971\end{array}$ & $\begin{array}{l}\$ 75,000 \\
-\$ 84,999\end{array}$ & $\begin{array}{l}\$ 60,000 \\
-\$ 74,999\end{array}$ & $\begin{array}{l}\$ 34,800 \\
-\$ 78,378\end{array}$ \\
\hline
\end{tabular}

Notes: Asterisk (*) indicates significant difference between sample Gulf and non-Gulf oyster eaters. Dagger $(\dagger)$ indicates significant difference between sample Gulf oyster eaters and noneaters.

Source: U.S. Census Bureau (2016).

household and income category, and proportion tests for all others, using $P=0.05$ as cutoff) were found between Gulf and non-Gulf oyster eaters with regard to percent males, percent college graduates, and income category. Also, a significant difference was found between Gulf oyster eaters and non-oyster eaters with regard to percent males. A rigorous statistical comparison of the sample to the population of interest is challenging. First, the population of interest is the set of individuals that eat raw oysters, but we are not aware of any set of statistics describing the composition of this population, and it is not known if or how this population differs from the general population. Second, our sample is composed of respondents from 20 different U.S. MSAs with vastly differing demographic compositions. Thus, we have no definitive indicators of the composition of our population of interest, and our best proxy for it-the composition of the general population of our study MSAs-varies widely. The best we can do, then, is to compare our sample statistics with the range of census statistics reported across the 20 MSAs. Table 2 reports these ranges, broken down into Gulf and non-Gulf subgroups (U.S. Census Bureau, 2016). We find that our sample statistics fall within the range for persons per household, percent college graduates, and income category, but outside of the range for percent persons aged $65+$, percent males, percent whites (outside the range for Gulf only), and percent high school graduates. 
Respondents were asked to indicate the frequency of raw-oyster consumption. Forty-one percent indicated one to two times per year, $40 \%$ indicated three to four times per year, and 19\% indicated more than four times per year. Responses were similar between Gulf and non-Gulf respondents. Respondents were then asked to indicate the quantity of raw oysters consumed in a typical meal. Among Gulf respondents, $44 \%$ indicated a dozen, 35\% indicated a half dozen, $11 \%$ indicated more than a dozen, and $10 \%$ indicated less than a half dozen. Among non-Gulf respondents, $44 \%$ indicated a half dozen, $32 \%$ indicated a dozen, $18 \%$ indicated less than a half dozen, and $6 \%$ indicated more than a dozen.

\subsection{Quality and Seafood Safety Ratings}

Table 3 contains the mean oyster quality and seafood safety ratings and proportion of “Don't Know” responses among Gulf and non-Gulf respondents, respectively. Regarding oyster quality ratings, Gulf respondents tended to give the highest ratings to Apalachicola Bay, Florida; coastal Louisiana; Cape Cod, Massachusetts; and Chesapeake Bay, Virginia (based on pairwise $t$-tests with a $P=0.05$ cutoff, the ratings of these four were statistically equivalent and, with few exceptions, significantly higher than the ratings of all others). Long Island Sound was rated lower than all other locations (and this finding was statistically significant), although Gulf respondents rated all other Atlantic locations higher than Pacific locations. Gulf respondents rated all other Atlantic locations higher than Pacific locations (although the differences were not statistically significant). Regarding the proportion of "Don't Know" responses, those of Long Island Sound and the Pacific coast locations were significantly higher than the remaining locations (based on pairwise tests of proportions), that of Gulf of Mexico was significantly higher than all others, and that of coastal Louisiana was significantly higher than all except Apalachicola Bay. Turning to seafood safety, Gulf respondents tended to rate Atlantic locations highest (Cape Code was significantly higher than all other locations, followed by Chesapeake Bay, whose mean rating was significantly higher than the remaining ones). Gulf respondents tended to rate the seafood safety of Atlantic locations highest (with the exception of Long Island Sound) and rated Pacific locations as high as or higher than Gulf locations. As with the quality ratings, Apalachicola Bay and coastal Louisiana fared better relative to other Gulf locations (the ratings of Apalachicola Bay, coastal Louisiana, and the Pacific coast locations were statistically equivalent, but significantly higher than other Gulf locations and Long Island Sound). Significant differences across proportions of “Don't Know” responses were consistent with those of oyster quality reported previously.

Non-Gulf respondents tended to rate the quality of oysters from Cape Cod the highest and those from all Gulf locations (except for coastal Louisiana) the lowest. The mean quality rating of Cape Cod was significantly greater than all other locations. Chesapeake Bay, coastal Oregon, and Puget Sound were statistically equivalent, and, with a few exceptions, significantly higher 
Table 3. Mean Ratings of Perceived Oyster Quality and Seafood Safety of Oyster-Harvest Bodies of Water

\begin{tabular}{|c|c|c|c|c|c|c|c|c|}
\hline \multirow[b]{3}{*}{ Location } & \multicolumn{4}{|c|}{ Perceived Oyster Quality Rating } & \multicolumn{4}{|c|}{ Perceived Seafood Safety Rating } \\
\hline & \multicolumn{2}{|c|}{$\begin{array}{c}\text { Gulf } \\
\text { Respondents }\end{array}$} & \multicolumn{2}{|c|}{$\begin{array}{c}\text { Non-Gulf } \\
\text { Respondents }\end{array}$} & \multicolumn{2}{|c|}{$\begin{array}{c}\text { Gulf } \\
\text { Respondents }\end{array}$} & \multicolumn{2}{|c|}{$\begin{array}{c}\text { Non-Gulf } \\
\text { Respondents }\end{array}$} \\
\hline & $\begin{array}{l}\text { Mean } \\
\text { Rating }\end{array}$ & $\begin{array}{l}\text { Don't } \\
\text { Know } \\
(\%)\end{array}$ & $\begin{array}{l}\text { Mean } \\
\text { Rating }\end{array}$ & $\begin{array}{l}\text { Don't } \\
\text { Know } \\
(\%)\end{array}$ & $\begin{array}{l}\text { Mean } \\
\text { Rating }\end{array}$ & $\begin{array}{l}\text { Don't } \\
\text { Know } \\
(\%)\end{array}$ & $\begin{array}{l}\text { Mean } \\
\text { Rating }\end{array}$ & $\begin{array}{l}\text { Don't } \\
\text { Know } \\
(\%)\end{array}$ \\
\hline $\begin{array}{l}\text { Apalachicola } \\
\text { Bay, Florida }\end{array}$ & 7.2 & 19 & 5.7 & 33 & 7.3 & 26 & 6.1 & 38 \\
\hline $\begin{array}{l}\text { Coastal } \\
\text { Louisiana }\end{array}$ & 7.3 & 18 & 6.5 & 23 & 7.1 & 24 & 6.2 & 28 \\
\hline $\begin{array}{l}\text { Galveston Bay, } \\
\text { Texas }\end{array}$ & 6.6 & 26 & 5.4 & 31 & 6.6 & 28 & 5.6 & 36 \\
\hline $\begin{array}{l}\text { Mississippi } \\
\text { Sound, } \\
\text { Mississippi }\end{array}$ & 6.6 & 27 & 5.7 & 29 & 6.8 & 30 & 5.8 & 34 \\
\hline $\begin{array}{c}\text { Mobile Bay, } \\
\text { Alabama }\end{array}$ & 6.7 & 25 & 5.6 & 28 & 6.8 & 28 & 5.6 & 35 \\
\hline Gulf of Mexico & 6.9 & 14 & 5.5 & 26 & 6.7 & 21 & 5.3 & 28 \\
\hline $\begin{array}{l}\text { Cape Cod, } \\
\text { Massachusetts }\end{array}$ & 7.3 & 28 & 7.8 & 17 & 7.6 & 33 & 7.7 & 22 \\
\hline $\begin{array}{l}\text { Chesapeake Bay, } \\
\text { Virginia }\end{array}$ & 7.2 & 26 & 7.3 & 18 & 7.4 & 32 & 7.3 & 24 \\
\hline $\begin{array}{l}\text { Long Island } \\
\text { Sound, New } \\
\text { York }\end{array}$ & 5.8 & 37 & 6.2 & 19 & 6.4 & 39 & 6.3 & 25 \\
\hline $\begin{array}{l}\text { Coastal } \\
\text { Northern } \\
\text { California }\end{array}$ & 6.3 & 37 & 6.7 & 26 & 6.9 & 41 & 7.2 & 29 \\
\hline Coastal Oregon & 6.5 & 37 & 7.2 & 26 & 7.2 & 39 & 7.4 & 30 \\
\hline $\begin{array}{l}\text { Puget Sound, } \\
\text { Washington }\end{array}$ & 6.8 & 36 & 7.2 & 25 & 7.1 & 40 & 7.6 & 29 \\
\hline
\end{tabular}

Notes: Ratings are from 1 (poor) to 10 (excellent). Proportion of "Don't Know" responses also reported.

than all others. Coastal Louisiana was statistically equivalent to Northern California and Long Island Sound, and rated significantly higher than all other Gulf locations. Mean ratings for Gulf of Mexico and Galveston Bay were generally significantly lower than all others. The proportion of "Don't Know" responses was significantly different for the Atlantic coast locations and coastal Louisiana compared with Apalachicola Bay and Galveston Bay, whereas those with intermediate proportions were not significantly different from each other.

Turning to seafood safety, non-Gulf respondents tended to rate Cape Cod and Puget Sound, Washington, highest, followed by other Atlantic and Pacific locations (the mean ratings for Cape Cod, Chesapeake Bay, and the Pacific coast 
locations were generally statistically equivalent and significantly higher than all others), with Gulf locations receiving the lowest ratings. Again, Apalachicola Bay and coastal Louisiana fared better than the other Gulf locations (the ratings of Apalachicola Bay and coastal Louisiana were statistically equivalent and significantly greater than all other Gulf coast locations). Significant differences across proportions of “Don't Know” responses were consistent with those of oyster quality reported previously. ${ }^{11}$

\subsection{Regression Results}

Table 4 contains the results of the random parameters logit regression models. A two-step approach was followed to arrive at the final reported models. First, each model was estimated with all coefficients on Gulf oyster varieties (and, for the generic treatment model, the non-Gulf oyster varieties coefficient as well) specified as random, all normally distributed. Those for which no evidence of preference heterogeneity was found (i.e., the standard deviation of the random coefficient was not significantly different from zero) were respecified as fixed, and the was model reestimated. ${ }^{12}$ Both first- and second-step model results were tested for sensitivity to the number of Halton draws used during estimation; results stabilized at about 400-500 draws. Reported results are those corresponding to 500 Halton draws.

Under the nongeneric treatments, we specified the base as containing all nonGulf coast oyster varieties, and for the other attributes, the base levels were medium-sized, mildly salty, and cultivated oysters. The reported coefficients indicate relative preferences for all other oyster varieties and attribute levels relative to these base levels.

The first two columns of Table 4 contain the results for the nongeneric treatment over the sample of non-Gulf respondents. Initial model results indicated significant preference heterogeneity for Apalachicola Bay (Florida) and Champagne Bay (Louisiana) oyster varieties only. Thus, only these varieties were

11 We wish to speak briefly about two issues specific to Gulf oysters that may have influenced responses. These are any perceived effects regarding of the 2010 Deepwater Horizon oil spill and that of Vibrio vulnificus. Although we did not elicit any responses specific to these two issues, we did include an open-ended question immediately following the choice experiment, food safety ratings, and quality ratings questions that asked, "While answering the previous questions, did you have any particular concerns about any of the oysters that had a big influence on your choices?" Although most respondents typically opt out of leaving comments (in the present survey, $46 \%$ of all respondents left it completely blank and another $14 \%$ said some variant of no), we conducted a keyword search for the following terms: "oil," "BP," "spill," "Deepwater," "Vibrio," and "bacteria." One of the oil-related terms appeared 40 times (23 times among Gulf respondents and 17 times among non-Gulf respondents), and a Vibrio-related term appeared 5 times (4 times among Gulf respondents and once among non-Gulf respondents). It is an open question as to whether the frequency of oil-related comments is of concern. Forty is just over $5 \%$ of the total number of respondents, but $14 \%$ when limited to those respondents who left a comment of some kind.

12 Respecifying the model as described had no substantial effects on other model results and yielded more efficient welfare estimates (i.e., smaller variances) for those variables respecified. 
Table 4. Random Parameters Logit Regression Estimates

\begin{tabular}{|c|c|c|c|c|c|c|}
\hline & \multicolumn{4}{|c|}{ Nongeneric Treatment } & \multirow{2}{*}{\multicolumn{2}{|c|}{$\begin{array}{c}\text { Generic Treatment } \\
\text { Gulf } \\
\text { Respondents }\end{array}$}} \\
\hline & \multicolumn{2}{|c|}{$\begin{array}{l}\text { Non-Gulf } \\
\text { Respondents }\end{array}$} & \multicolumn{2}{|c|}{$\begin{array}{c}\text { Gulf } \\
\text { Respondents }\end{array}$} & & \\
\hline & Coefficient & $\begin{array}{l}\text { Standard } \\
\text { Error }\end{array}$ & Coefficient & $\begin{array}{l}\text { Standard } \\
\text { Error }\end{array}$ & Coefficient & $\begin{array}{l}\text { Standard } \\
\text { Error }\end{array}$ \\
\hline $\operatorname{Ln}($ Price $)$ & $-2.40^{* * *}$ & 0.07 & $-2.19^{* * *}$ & 0.12 & $-2.39^{* * *}$ & 0.13 \\
\hline Apalachicola Bay & $-0.49^{* * *}$ & 0.10 & 0.46 & 0.30 & $0.70^{* * *}$ & 0.22 \\
\hline $\begin{array}{l}\text { Standard } \\
\text { deviation }\end{array}$ & $0.67^{* * *}$ & 0.18 & $1.72^{* * *}$ & 0.42 & $2.04^{* * *}$ & 0.34 \\
\hline $\begin{array}{l}\text { Bay Saint Louis } \\
\text { Standard } \\
\text { deviation }\end{array}$ & $-0.58^{* * *}$ & 0.10 & $\begin{array}{l}0.48^{*} \\
1.29^{* * *}\end{array}$ & $\begin{array}{l}0.27 \\
0.37\end{array}$ & 0.03 & 0.12 \\
\hline Champagne Bay & $-0.24^{* *}$ & 0.10 & $0.78^{* * *}$ & 0.29 & $0.30^{*}$ & 0.16 \\
\hline $\begin{array}{l}\text { Standard } \\
\text { deviation }\end{array}$ & $0.60^{* * *}$ & 0.22 & $1.47^{* * *}$ & 0.33 & $1.16^{* * *}$ & 0.23 \\
\hline $\begin{array}{l}\text { Lonesome Reef } \\
\text { Standard } \\
\text { deviation }\end{array}$ & $-0.46^{* * *}$ & 0.10 & $\begin{array}{l}0.65^{*} \\
1.74^{* * *}\end{array}$ & $\begin{array}{l}0.35 \\
0.42\end{array}$ & $\begin{array}{l}-0.02 \\
1.18^{* * *}\end{array}$ & $\begin{array}{l}0.17 \\
0.21\end{array}$ \\
\hline $\begin{array}{l}\text { Point aux Pins } \\
\text { Standard } \\
\text { deviation }\end{array}$ & $-0.48^{* * *}$ & 0.10 & $\begin{array}{l}0.35 \\
1.59^{* * *}\end{array}$ & $\begin{array}{l}0.30 \\
0.40\end{array}$ & $\begin{array}{l}-0.22 \\
0.75^{* *}\end{array}$ & $\begin{array}{l}0.16 \\
0.32\end{array}$ \\
\hline Portersville Bay & $-0.54^{* * *}$ & 0.10 & -0.18 & 0.23 & -0.25 & 0.15 \\
\hline $\begin{array}{l}\text { Non-Gulf } \\
\text { varieties }\end{array}$ & & & & & $-0.40^{*}$ & 0.21 \\
\hline $\begin{array}{l}\text { Standard } \\
\text { deviation }\end{array}$ & & & & & $2.85^{* * *}$ & 0.19 \\
\hline Small size & $-0.50^{* * *}$ & 0.09 & $-0.42^{*}$ & 0.22 & $-0.70^{* * *}$ & 0.16 \\
\hline Large size & -0.11 & 0.08 & -0.28 & 0.21 & 0.10 & 0.18 \\
\hline Sweet & 0.06 & 0.09 & 0.17 & 0.22 & -0.10 & 0.17 \\
\hline Salty & $-0.51^{* * *}$ & 0.08 & 0.14 & 0.21 & 0.05 & 0.15 \\
\hline Wild & $0.19^{* * *}$ & 0.07 & $0.33^{* *}$ & 0.15 & $0.41^{* * *}$ & 0.11 \\
\hline $\begin{array}{l}\text { No. choice } \\
\text { observations }\end{array}$ & & 2,937 & & 1,059 & 2,992 & \\
\hline No. respondents & & 269 & & 100 & 344 & \\
\hline Log likelihood & & $-2,506.21$ & & -877.93 & $-2,211.31$ & \\
\hline $\begin{array}{l}\text { Akaike } \\
\text { information } \\
\text { criterion }\end{array}$ & & $5,040.4$ & & $1,789.9$ & $4,458.6$ & \\
\hline
\end{tabular}

Note: Asterisks $\left({ }^{* * *},{ }^{* *},{ }^{*}\right)$ indicate significance at the $1 \%, 5 \%$, and $10 \%$ levels, respectively.

specified as having random coefficients in the final model reported. The random coefficients logit model allows for estimation of respondent-specific preference parameters. Parsing these individualized parameters into two groups, those with positive coefficients and those with negative coefficients, indicates that $97 \%$ had a negative coefficient for Apalachicola Bay oysters, whereas 3\% had a positive coefficient; $86 \%$ had a negative coefficient for Champagne Bay oysters, whereas 
$14 \%$ had a positive coefficient. In other words, although there was significant heterogeneity across respondents with regard to their preferences for these two oyster varieties, most respondents had negative preferences for them relative to the base (non-Gulf) oyster varieties. As expected, then, the means of the coefficients for these two varieties were found to be significant and negative. For the remaining Gulf oyster varieties, the coefficients were significant and negative as well, indicating that these varieties were significantly less likely to be chosen relative to the base. Regarding the coefficients on taste, size, and production method, results indicate that small-sized and salty oysters were significantly less likely to be chosen, whereas wild-caught oysters were significantly more likely to be chosen.

The third and fourth columns of Table 4 contain the results for the nongeneric treatment over the sample of Gulf respondents. Results indicate significant preference heterogeneity for all Gulf oyster varieties except for Portersville Bay (Alabama). The breakdown of individual respondent coefficients is $65 \%$ with a positive coefficient and 35\% with a negative coefficient for Apalachicola Bay; $73 \%$ positive and $27 \%$ negative for Bay St. Louis (Mississippi); $83 \%$ positive and $17 \%$ negative for Champagne Bay; $80 \%$ positive and $20 \%$ negative for Lonesome Reef (Texas); and 67\% positive and 33\% negative for Point aux Pins (Alabama). The mean of the coefficients on Apalachicola Bay and Point aux Pins were not statistically different from zero, and those of Bay St. Louis and Lonesome Reef are only marginally significant, leaving Champagne Bay as the only variety specified with a random coefficient as having a highly significant positive mean effect. Also, the coefficient on Portersville Bay was not statistically different from zero.

Under the generic treatment, each choice set included a fixed third alternative representing a generic (i.e., commodity) Gulf of Mexico oyster. All non-Gulf coast oyster varieties were pooled into a single category under the "non-Gulf varieties" attribute. As before, for the other attributes, the base levels were medium-sized, mildly salty, and cultivated oysters. The reported coefficients indicate relative preferences for all other oyster varieties relative to the base. For the other attributes, the reported coefficients indicate relative preferences for other branded oysters with the base attribute levels.

The last two columns of Table 4 contain the results for the generic treatment over the sample of Gulf respondents. Initial model results indicated significant preference heterogeneity for all oyster varieties except for Bay St. Louis and Portersville Bay. Thus, all varieties except these two were specified as having random coefficients in the final model reported. The breakdown of individual respondent coefficients was $72 \%$ with positive preferences (i.e., a positive coefficient) and $28 \%$ with negative preferences for Apalachicola Bay; $79 \%$ with positive preferences and $21 \%$ with negative preferences for Champagne Bay oysters; $30 \%$ with positive preferences and $70 \%$ with negative preferences for Lonesome Reef oysters; $14 \%$ with positive preferences and $86 \%$ with 
negative preferences for Point aux Pins oysters. The mean of the coefficient for Apalachicola Bay was found to be highly significant and positive, whereas that of Champagne Bay was found to be positive as well but only marginally significant. Although a large majority of respondent coefficients were estimated to be negative, the means of the coefficients on Lonesome Reef and Point aux Pins were not significantly different from zero. The (fixed) coefficients on Bay St. Louis and Portersville Bay were not significantly different from zero either. Regarding the coefficients on taste, size, and production method, results indicate that small-sized oysters were significantly less likely to be chosen, whereas wildcaught oysters were significantly more likely to be chosen.

\subsection{Welfare Estimates}

Mean WTP a premium for a given oyster alternative is defined as the ratio of the associated coefficient and the exponential of the price coefficient. Confidence intervals were calculated using the Delta method following Bliemer and Rose (2013). For reference, oyster varieties averaged \$13 per half dozen in the survey, so the reported dollar values can be interpreted as premia (or discounts) added to this price.

Table 5 contains the mean maximum WTP a premium for a given oyster variety over and above the price of the base oyster varieties, as well as $95 \%$ confidence intervals around those means, based on the random coefficients regression results. The welfare estimates for attributes with significant preference heterogeneity tend to have very wide confidence intervals. Attributes whose regression coefficients were significantly different from zero are marked with an asterisk in Table 5, implying WTP estimates significantly different from zero. Those without asterisks are treated in the discussion as statistically equal to zero (i.e., fetching neither a price premium nor discount).

Under the nongeneric treatment administered to non-Gulf respondents, all Gulf varieties are estimated to require a price discount relative to base nonGulf varieties. Champagne Bay oysters require the smallest discount, whereas the remaining Gulf varieties require substantially larger discounts. Note, however, that because of the significant preference heterogeneity found for Apalachicola Bay and Champagne Bay oysters, the confidence intervals on these varieties are very wide, whereas the confidence intervals on the remaining Gulf varieties span a few dollars on either side of the mean. Results also indicate that small oysters, as well as salty oysters, come at a price discount. Wild-caught oysters are found to fetch a price premium over the base cultivated oysters.

Among Gulf respondents, Bay St. Louis, Champagne Bay, and Lonesome Reef varieties are estimated to fetch a mean price premium relative to non-Gulf varieties, although given the significant preference heterogeneity, the confidence intervals are very wide and span both sides of zero. Results also indicate that small oysters come at a price discount. No other varieties or attributes were 
Table 5. Marginal Willingness-to-Pay Estimates Based on Random Coefficients Logit Results, Amounts Represent Dollar Premium per Half Dozen Oysters over and above Price of Base Oyster (for nongeneric treatments, non-Gulf varieties; for generic treatment, generic Gulf oyster)

\begin{tabular}{|c|c|c|c|}
\hline & \multicolumn{2}{|l|}{ Nongeneric Treatment } & Generic Treatment \\
\hline & \multicolumn{2}{|l|}{ Non-Gulf Respondents } & spondents \\
\hline & \multicolumn{2}{|c|}{ Base: Non-Gulf Varieties } & \multirow{2}{*}{$\begin{array}{l}\text { Base: Generic Gulf Oyster } \\
\text { Mean Premium (95\% CI) }\end{array}$} \\
\hline & Mean Premium (95\% CI) & Mean Premium (95\% CI) & \\
\hline Apalachicola Bay & $y-\$ 5.45^{*}(-\$ 20.66, \$ 9.77)$ & $\$ 4.13(-\$ 27.56, \$ 35.82)$ & $\$ 7.65^{*}(-\$ 37.18, \$ 52.47)$ \\
\hline Bay Saint Louis & $-\$ 6.40^{*}(-\$ 8.46,-\$ 4.34)$ & $\$ 4.27^{*}(-\$ 19.87, \$ 28.40)$ & $\$ 0.31(-\$ 2.36, \$ 2.98)$ \\
\hline Champagne Bay & $-\$ 2.66^{*}(-\$ 16.56, \$ 11.23)$ & $\$ 6.93^{*}(-\$ 19.75, \$ 33.61)$ & $\$ 3.26^{*}(-\$ 22.48, \$ 28.99)$ \\
\hline Lonesome Reef & $-\$ 5.11^{*}(-\$ 7.09,-\$ 3.15)$ & $\$ 5.76^{*}(-\$ 26.15, \$ 37.67)$ & $-\$ 0.26(-\$ 26.21, \$ 25.68)$ \\
\hline Point aux Pins & $-\$ 5.26^{*}(-\$ 7.40,-\$ 3.13)$ & $\$ 3.10(-\$ 26.12, \$ 32.32)$ & $-\$ 2.40(-\$ 20.37, \$ 15.58)$ \\
\hline Portersville Bay & $-6.01^{*}(-\$ 8.09,-\$ 3.94)$ & $-\$ 1.62(-\$ 5.50, \$ 2.25)$ & $-\$ 2.70(-\$ 5.92, \$ 0.51)$ \\
\hline Small size $†$ & $-\$ 5.49^{*}(-\$ 7.46,-\$ 3.51)$ & $-\$ 3.72^{*}(-\$ 7.49, \$ 0.05)$ & $-\$ 7.68^{*}(-\$ 11.41,-\$ 3.94)$ \\
\hline Large size† & $-\$ 1.22(-\$ 3.07, \$ 0.63)$ & $-\$ 2.50(-\$ 6.20, \$ 1.21)$ & $\$ 1.08(-\$ 2.85, \$ 5.01)$ \\
\hline Sweet $\uparrow$ & $\$ 0.62(-\$ 1.40, \$ 2.64)$ & $\$ 1.51(-\$ 2.39, \$ 5.42)$ & $-\$ 1.06(-\$ 4.64, \$ 2.52)$ \\
\hline Salty† & $-\$ 5.64^{*}(-\$ 7.32,-\$ 3.96)$ & $\$ 1.20(-\$ 2.47, \$ 4.87)$ & $\$ 0.53(-\$ 2.66, \$ 3.72)$ \\
\hline Wild & $\$ 2.05^{*}(\$ 0.46, \$ 3.64)$ & $\$ 2.91(\$ 0.13, \$ 5.68)$ & $\$ 4.42^{*}(\$ 1.76, \$ 7.08)$ \\
\hline
\end{tabular}

Notes: Asterisk $\left(^{*}\right)$ indicates attributes whose (mean) coefficients reported in Table 3 were significantly different from zero, implying that the mean WTP estimates reported here are significantly different from zero. Dagger $(\dagger)$ indicates that for these attributes only, the reported value should be interpreted as the willingness to pay a premium over and above the price of an alternative oyster having the base attribute level (i.e., medium size, mildly salty, or cultivated, respectively). For the generic treatment, it is relative to an alternative branded oyster having the base attribute level. CI, confidence interval.

found to significantly affect price among Gulf respondents under the nongeneric treatment.

Under the generic treatment, administered to Gulf respondents only, Apalachicola Bay and Champagne Bay varieties are estimated to fetch a mean price premium relative to generic Gulf oysters but, given the significant preference heterogeneity, have very wide confidence intervals spanning both sides of zero. Results also indicate that small oysters come at a price discount, whereas wildcaught oysters come at a price premium.

\section{Discussion and Conclusions}

Here we summarize the key findings based on our sample of how consumers are likely to respond to branded Gulf oysters. Responses to questions regarding perceptions indicate that Gulf consumers tend to perceive the quality of oysters and overall safety of seafood from Apalachicola Bay and coastal Louisiana higher than that of other Gulf, Atlantic, and Pacific water bodies. Consumers in non-Gulf markets on the other hand tend to perceive the quality of oysters and 
safety of seafood from Gulf water bodies as worse than that of Atlantic and Pacific locations, although Apalachicola Bay and coastal Louisiana appear to rate higher than other Gulf locations. At the same time, we observed more "I don't know" responses to these questions by respondents in non-Gulf markets, indicating that consumers from these markets are more likely to have no or less well-formed opinions on Gulf oysters.

The nongeneric treatment of the choice experiment attempted to capture the potential effects of introducing branded Gulf oysters into non-Gulf markets, such as those along the Atlantic and Pacific coasts. Results indicate that consumers in non-Gulf markets are less likely to choose Gulf oysters relative to non-Gulf varieties. However, results also indicate significant preference heterogeneity for Champagne Bay (Louisiana) and Apalachicola Bay (Florida) oysters, indicating that although most non-Gulf consumers are likely to hold negative preferences for these two varieties, at least some proportion are likely to hold positive preferences for them. This finding is consistent with the perception responses discussed previously, where these two varieties rated higher than other Gulf varieties. Additionally, small-sized oysters appear less likely to be chosen and wild-caught oysters appear more likely to be chosen by consumers in non-Gulf markets.

Results for the nongeneric treatment administered to respondents in Gulf markets indicate widespread preference heterogeneity across Gulf oyster varieties, meaning that preferences for each variety are likely to vary widely from person to person. Champagne Bay oysters performed best of all Gulf varieties, although significant positive preferences were found for Bay St. Louis (Mississippi) and Lonesome Reef (Galveston Bay, Texas) varieties. As before, small-sized oysters were less preferred, and wild-caught oysters were more preferred.

The generic treatment administered to respondents in Gulf markets attempts to capture the potential of Gulf consumers to pay a premium for branded Gulf oysters over the common generic (i.e., commodity) Gulf oysters. Results indicate significant preference heterogeneity among most Gulf varieties. However, significant positive preferences were found for Apalachicola Bay (Florida) and Champagne Bay (Louisiana) varieties. Also, as before, it appears that consumers in Gulf markets are likely to have a strong distaste for small-sized oysters and a strong preference for wild-caught oysters. Comparing results for Gulf consumers between nongeneric and generic treatments, we see fairly consistent results, especially regarding strong performance of Champagne Bay, although Bay Saint Louis and Lonesome Reef performed relatively better under the nongeneric treatment, whereas Apalachicola Bay performed better under the generic treatment.

In terms of WTP a premium for branded Gulf varieties, the results from our sample indicate that consumers are likely to require a price discount relative to non-Gulf varieties, on the order of $\$ 3-\$ 6$ per half dozen. Using the mean 
branded variety price of $\$ 13$ per half dozen used during the choice experiment, this implies that Gulf varieties might sell retail at $\$ 7-\$ 10$ per half dozen in non-Gulf markets, depending on the specific variety and other factors. ${ }^{13}$ For example, results indicate that wild-caught oysters may fetch a premium of $\$ 2$ per half dozen over farm-raised oysters independent of the brand. It is important to stress, however, the fairly wide confidence intervals on some of these estimates, indicating that the true price premia may lie far outside the levels indicated by the means here.

Among Gulf respondents, we estimate positive price premia for branded varieties on the order of $\$ 0-\$ 8$ per half dozen $(\$ 0-\$ 3$ per half dozen if the outlying Apalachicola Bay estimate is omitted). Using the mean price of $\$ 9$ per half dozen for generic Gulf oysters as used in the choice experiment, there is implied a retail price of $\$ 9-\$ 17$ per half dozen $(\$ 9-\$ 12$ if Apalachicola Bay is omitted) for branded Gulf varieties. ${ }^{14}$ The same caveat about taking into account the wide confidence intervals around these means applies here as well.

Overall, results are indicative of a universal preference for oysters originating from one's own region, as evidenced by the almost complete reversal of model coefficients and welfare estimates for Gulf varieties from non-Gulf to Gulf samples. Although interesting, this finding is not particularly surprising and not really the point of this study. Rather, the point is to understand the relative preferences of Gulf oysters, and to identify any specific Gulf varieties and/or attributes that perform relatively better (or worse) among the different set of consumers, in order to identify the most likely avenues for market development. In this regard, we find that among Gulf varieties, Champagne Bay (Louisiana) and Apalachicola Bay (Florida) stood out as relatively preferred over the other Gulf varieties tested, small-sized oysters were significantly less preferred, and wildcaught oysters were significantly more preferred. Thus, if market opportunities do exist for branded Gulf oysters, the present results indicate that the greatest promise may lie with Florida and Louisiana oysters. This finding may be at least partially explained, however, by the fact that Florida and Louisiana are more widely recognized for their seafood than the other Gulf states. Thus, our results are not meant to discount the market potential of the oysters from Alabama, Mississippi, and Texas, but rather to imply that the successful marketing of oysters from these states may require a more nuanced marketing and branding strategy. For example, Gulf oysters tend to grow larger than

13 As of September 2, 2015, branded oyster varieties were selling at the following prices per half dozen at the following Atlantic and Pacific coast restaurants: Island Creek Oyster Bar (Boston), \$15-\$21; Grand Central Oyster Bar (New York), \$12.90-\$22.50; Shaw's Crab House (Chicago), \$18; and Elliott's Oyster House (Seattle), \$16.50-\$21.

14 As of September 2, 2015, (generic) Gulf oysters were selling at the following prices per half dozen at the following Gulf coast restaurants: Liberty Kitchen \& Oyster Bar (Houston), \$10.25; Felix's (New Orleans), \$8.75; Wintzell’s Oyster House (Mobile), \$9.99; Atlas Oyster House (Pensacola), \$6.95; and The Oyster Bar (Tampa Bay), \$9. 
non-Gulf oysters, and Gulf oyster production is predominated by wild-caught oysters in contrast to non-Gulf oyster production, which is predominated by farm-raised oysters. Given that our results show strong preferences for wildcaught and relatively larger oysters, marketing strategies could highlight these two attributes. Furthermore, given that a substantial share of respondents in non-Gulf markets indicated no clear opinions on the quality and safety of Gulf waters (i.e., they responded "I don't know" to such questions), there may be some opportunity to sway currently uninformed consumer opinion.

\section{References}

Bishop, M.J., and C.H. Peterson. "Consumer Rating of the Suminoe Oyster, Crassostrea Ariakensis, during Home Cooking." Journal of Shellfish Research 24,2(2005):497-502.

Bliemer, M.C.J., and J.M. Rose. "Confidence Intervals of Willingness-to-Pay for Random Coefficient Logit Models." Transportation Research Part B: Methodological 58(December 2013):199-214.

Bruner, D., W. Huth, D.M. McEvoy, and O.A. Morgan. "Accounting for Tastes: A Valuation of Risk Reduction in Raw Seafood Consumption.” Department of Economics Working Paper No. 11-09, Boone, NC: Department of Economics, Appalachian State University, 2011.

Carson, R.T., and M. Czajkowski. "A New Baseline Model for Estimating Willingness to Pay from Discrete Choice Models.” Paper presented at the 2013 International Choice Modelling Conference, Sydney, Australia, July 3-5, 2013. Internet site: http://www. icmconference.org.uk/index.php/icmc/ICMC2013/paper/view/730 (Accessed December 9, 2014).

Chapman, R.G., and R. Staelin. "Exploiting Rank Ordered Choice Set Data within the Stochastic Utility Model.” Journal of Marketing Research 19(August 1982):288-301.

ChoiceMetrics. Ngene 1.1.1 User Manual \& Reference Guide. Sydney, Australia: ChoiceMetrics, 2012.

Dedah, C., W.R. Keithly, Jr., and R.F. Kazmierczak, Jr. “An Analysis of US Oyster Demand and the Influence of Labeling Requirements.” Marine Resource Economics 26,1(2011): $17-33$.

Flynn, T.N., J.J. Louviere, T.J. Peters, and J. Coast. "Best-Worst Scaling: What It Can Do for Health Care Research and How to Do It." Journal of Health Economics 26,1(2007):171-89.

Flynn, T.N., and A.A.J. Marley. "Best-Worst Scaling: Theory and Methods." Handbook of Choice Modelling. S. Hess and A. Daly, eds. Cheltenham, UK: Edward Elgar, 2014, pp. 178-201.

Grabowski, J.H., S.P. Powers, C.H. Peterson, M.J. Powers, and D.P. Green. “Consumer Ratings of Non-Native (Crassostrea gigas and Crassostrea ariakensis) vs. Native (Crassostrea virginica) Oysters." Journal of Shellfish Research 22,1(2003):21-30.

Greene, W.H. Reference Guide: NLOGIT Version 5.0. Plainview, NY: Econometric Software Inc., 2012.

House, L., T.R. Hanson, and S. Sureshwaran. "U.S. Consumers: Examining the Decision to Consume Oysters and the Decision of How Frequently to Consume Oysters." Journal of Shellfish Research 22,1(2003):51-59. 
Jacobsen, R. “The Oyster Guide.” 2016. Internet site: http://www.oysterguide.com/maps/ gulf-coast (Accessed February 17, 2011).

Kecinski, M., K.D. Messer, and A.J. Peo. Consumer Preferences for the Provision of Water Quality Services by Oysters. Newark: Department of Applied Economics and Statistics (APEC), College of Agriculture and Natural Resources, University of Delaware, APEC Research Report RR16-02, March 2016.

Keithly, W.R., and H. Diop. "The Demand for Eastern Oysters, Crassostrea virginica, from the Gulf of Mexico in the Presence of Vibrio vulnificus." Marine Fisheries Review 63,1(2001):47-53.

Kow, F., L. Yu, D. FitzGerald, and D. Grewal. "Understanding the Factors Related to the Consumers' Choices of Oysters in Australia: An Empirical Study." Journal of Food Service 19,4(2008):245-53.

Lancaster, K.J. “A New Approach to Consumer Theory.” Journal of Political Economy 74,2(1966):132-57.

Lin, C.-T.J., and J.W. Milon. "Attitudes and Safety Perception in a Double-Hurdle Model of Shellfish Consumption.” American Journal of Agricultural Economics 75,3(1993):72429.

Lipton, D. "Economic Benefits of a Restored Oyster Fishery in Chesapeake Bay." Journal of Shellfish Research 27,3(2008):619-23.

Louviere, J.J., T.N. Flynn, and A.A.J. Marley. Best-Worst Scaling: Theory, Methods and Applications. Cambridge: Cambridge University Press, 2015.

Louviere, J.J., D.A. Hensher, and J. Swait. Stated choice methods: analysis and application. Cambridge, UK: Cambridge University Press, 2000.

Manalo, A.B., and C.M. Gempesaw II. "Preferences for Oyster Attributes by Consumers in the U.S. Northeast." Journal of Food Distribution Research 28,2(1997): 55-63.

Marley, A.A.J., and J.J. Louviere. "Some Probabilistic Models of Best, Worst, and Best-Worst Choices." Journal of Mathematical Psychology 49,6(2005):464-80.

Marschak, J. "Binary Choice Constraints on Random Utility Indications." Stanford Symposium on Mathematical Methods in the Social Sciences. K. Arrow, ed. Stanford, CA: Stanford University Press, 1960, pp. 312-29.

Martínez-Cordero, F.J., Q.S.W. Fong, and M.C. Haws. "Marketing Extension and Outreach in Sinaloa, Mexico: A Preliminary Analysis of Preferences for Oysters.” Marine Resource Economics 24,1(2009):89-95.

McFadden, D. “Conditional Logit Analysis of Qualitative Choice Behavior." Frontiers in Econometrics. P. Zarembka, ed. New York: Academic Press, 1974, pp. 105-42.

- "The Choice Theory Approach to Market Research." Marketing Science 5,4(1986):275-97.

McFadden, D., and K. Train. "Mixed MNL Models for Discrete Response.” Journal of Applied Econometrics 15,5(2000):447-70.

Morgan, O.A., G.S. Martin, and W.L. Huth. "Oyster Demand Adjustments to CounterInformation and Source Treatments in Response to Vibrio vulnificus." Journal of Agricultural and Applied Economics 41,3(2009):683-96.

Morgan, O.A., J.C. Whitehead, and W.L. Huth. "Accounting for Heterogeneity in Behavioural Responses to Health-Risk Information Treatments." Journal of Environmental Economics and Policy 5,3(2016):283-97.

Morgan, O.A., J.C. Whitehead, W.L. Huth, G.S. Martin, and R. Sjolander. “A SplitSample Revealed and Stated Preference Demand Model to Examine Homogeneous 
Subgroup Consumer Behavior Responses to Information and Food Safety Technology Treatments." Environmental and Resource Economics 54,4(2013):593-611.

National Marine Fisheries Service (NMFS). "Annual Commercial Landings Statistics: Eastern Oyster, 2013" [online database]. NMFS, Fisheries Statistics and Economics Division, 2014. Internet site: http://www.st.nmfs.noaa.gov/commercial-fisheries/ commercial-landings/annual-landings/index (Accessed August 12, 2015).

Nell, J.A., P.J. O'Riordan, and D.M. Ogburn. "Consumer Evaluation of Diploid and Triploid Pacific Oysters Subjected to High Pressure Treatment." Journal of Shellfish Research 25,3(2006):1101-4.

Petrolia, D.R. "Risk Preferences, Risk Perceptions, and Risky Food.” Food Policy 64(2016):3748.

Potoglou, D., P. Burge, T. Flynn, A. Netten, J. Malley, J. Forder, and J.E. Brazier. "Best-Worst Scaling vs. Discrete Choice Experiments: An Empirical Comparison Using Social Care Data." Social Science \& Medicine 72,10(2011):1717-27.

Rigby, D., M. Burton, and J.L. Lusk. "Journals, Preferences, and Publishing in Agricultural and Environmental Economics." American Journal of Agricultural Economics 97,2(2015):490-509.

Scarpa, R., S. Notaro, J. Louviere, and R. Raffaelli. "Exploring Scale Effects of Best/Worst Rank Ordered Choice Data to Estimate Benefits of Tourism in Alpine Grazing Commons.” American Journal of Agricultural Economics 93,3(2011):813-28.

Thurstone, L.L. “A Law of Comparative Judgement.” Psychological Review 34,4(1927):27386.

U.S. Census Bureau. “QuickFacts” [various cities]. Internet site: http://www.census.gov/ quickfacts/table/PST045215/00 (December 1, 2016).

Whitehead, J.C., O.A. Morgan, W.L. Huth, G.S. Martin, and R. Sjolander. "Willingness-toPay for Oyster Consumption Mortality Risk Reductions.” Department of Economics Working Paper No. 12-07, Boone, NC: Department of Economics, Appalachian State University, 2012. 